\title{
Thermodynamic Evolution of Cerium Oxide Nanoparticle Morphol- ogy using Carbon Dioxide.
}

\author{
Adam R. Symington, ${ }^{* a}$ Robert M. Harker, ${ }^{\mathrm{b}}$ Mark T. Storr, ${ }^{\mathrm{b}}$ Marco Molinari, ${ }^{\mathrm{c}}$ and Stephen C. Parker, ${ }^{* a}$ \\ ${ }^{a}$ Department of Chemistry, University of Bath, Claverton Down, Bath, BA2 7AY, UK \\ b AWE Aldermaston, Reading, RG7 4PR, UK \\ ${ }^{c}$ Department of Chemistry, University of Huddersfield, Queensgate, Huddersfield, HD1 3DH, UK
}

KEYWORDS (ceria, catalysis, carbon dioxide adsorption, carbonate formation)

\begin{abstract}
Surface morphology is known to affect catalytic activity, as some surfaces show greater activity than others. One of the key challenges is to identify strategies to enhance the expression of such surfaces and also to prevent their disappearance over time. Here, we apply density functional theory to the catalytic material $\mathrm{CeO}_{2}$ to predict the effect of adsorbed $\mathrm{CO}_{2}$ on the morphology of the material as a function of temperature and pressure. We predict that $\mathrm{CO}_{2}$ adsorbs as surface carbonates and that the magnitude of the adsorption energy is surface dependent, following the order $\{100\}>\{110\}>\{111\}$. We show that this difference leads to selective thermodynamic enhancement of $\{100\}$ surfaces as a function of $\mathrm{CO}_{2}$ partial pressure and temperature. Finally, we show how the calculated surface free energies as a function of external conditions can be deployed to predict changes in the equilibrium particle morphology. These include the prediction that ceria nanoparticles prepared in the presence of supercritical $\mathrm{CO}_{2}$ will favour enhanced cube-like morphologies.
\end{abstract}

\section{Introduction}

Controlling the size and morphology of nanoparticles is an important consideration when designing materials, particularly catalysts, ${ }^{1-8}$ not least because nanoparticle morphology and surface composition have a significant effect on reaction selectivity and reactivity. ${ }^{9-13}$ A good example of this effect can be seen with cerium dioxide (ceria, $\mathrm{CeO}_{2}$ ) nanoparticles, where the properties are influenced by their morphology and hence the particular surfaces expressed. Ceria finds applications in soot oxidation/three-way catalysts, ${ }^{14}$ water gas shift reactions, ${ }^{15-16}$ solid oxide fuel cells, ${ }^{17}$ and biomedicine. ${ }^{18}$

A variety of $\mathrm{CeO}_{2}$ nanoparticle morphologies are observed: octahedral, cubes and rods. ${ }^{17,19}$ The lowest energy $\{111\}$ surfaces form an octahedron and thus the nano-octahedron is the thermodynamically most stable form. ${ }^{20-22}$ In practice, different synthesis conditions access other morphologies. ${ }^{23-29}$ These include nano-cubes comprised of $\{100\}$ surfaces $^{30-31}$ and nano-rods comprised of a mixture of surfaces (the actual surface structure of rods has been the subject of considerable debate ${ }^{32}$ ). The $\{100\}$ and $\{110\}$ surfaces are higher in energy than the $\{111\}$ and thus nano-cubes and nano-rods are nominally less stable than nano-octahedra. As a result, nano-cubes and nano-rods might degrade over time and form less reactive nano-octahedra (Figure 1); ${ }^{21}$ surface faceting of ceria nanopowder and nanocubes has been demonstrated at $730^{\circ} \mathrm{C}{ }^{33}$ and $600^{\circ} \mathrm{C}{ }^{34}$ respectively. Clearly, having synthesised particles expressing particularly facets it is also useful to examine how to protect these shapes from degradation.
Some molecules, such as water, and hydroxyl groups when adsorbed at the surface of $\mathrm{CeO}_{2}$ nano-cubes can stabilise the reactive $\{100\}$ surfaces and thus, in theory, prevent the degradation of nano-cubes to nano-octahedra. ${ }^{20-21,30}$ However, despite the many studies on the adsorption of small molecules on ceria, key questions remain. For example, how do molecules present during synthesis, post-synthetic treatments or during catalytic processes, modify the expression and evolution of specific surfaces? ${ }^{35}$ Recent work on water adsorption has shown that water molecules stabilise the $\{100\}$ surface relative to the $\{111\}$ surface in $\mathrm{CeO}_{2}{ }^{21}$ But one molecule that has not been studied in this context is $\mathrm{CO}_{2}$. $\mathrm{CeO}_{2}$ comes into contact with $\mathrm{CO}_{2}$ in several applications and synthesis processes including three-way catalysts and soot oxidation catalysts, ${ }^{14,36}$ where $\mathrm{CO}$ oxidizes to $\mathrm{CO}_{2}$, in water gas shift reactions, where $\mathrm{H}_{2} \mathrm{O}+\mathrm{CO} \rightarrow \mathrm{H}_{2}+$ $\mathrm{CO}_{2}{ }^{15,37}$, and in dry reforming processes, where $\mathrm{CH}_{4}+\mathrm{CO}_{2} \rightarrow$ $2 \mathrm{CO}+2 \mathrm{H}_{2} \cdot 38-39$

Catalytic studies have shown that adsorption of $\mathrm{CO}_{2}$ can result in the formation of strongly bound surface carbonate species; carbonates are responsible for a reduction in the catalytic activity of ceria and this is known as carbonate poisoning. ${ }^{16-17,40-47}$ Computational work has shown that carbonate species can form at the surface ${ }^{48-49}$ but findings are complicated by the large differences in the behaviour of different surfaces. Surface carbonates are formed on many metal oxides such as Yttria Stabilized Zirconia (YSZ), ${ }^{50} \mathrm{ZrO}_{2},{ }^{50} \mathrm{MgO},{ }^{51} \mathrm{BaTiO}_{3},{ }^{52} \mathrm{TiO}_{2},{ }^{53-56}$ $\mathrm{Fe}_{2} \mathrm{O}_{3}{ }^{57-59}$ and $\mathrm{Al}_{2} \mathrm{O}_{3}{ }^{60}$ 


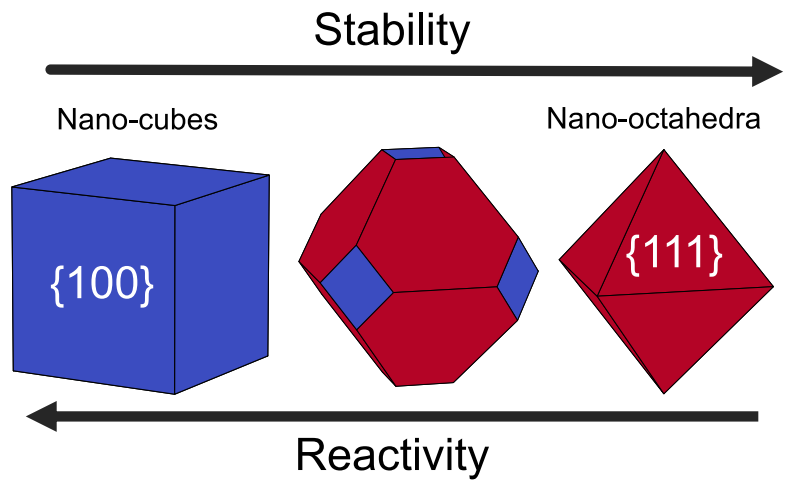

Figure 1- Schematic illustrating the relationship between nanoparticle shape and stability/reactivity. The $\{100\}$ and $\{111\}$ surfaces are represented by blue and red planes.

Thus, in this work we present a computational investigation of the interaction of carbon dioxide with the most important low index surfaces of $\mathrm{CeO}_{2}(\{111\},\{110\}$ and $\{100\})$, with particular emphasis on carbonate formation. Since the surfaces of ceria are often found to be oxygen deficient, we also consider how the adsorption of $\mathrm{CO}_{2}$ modifies the surface free energies of reduced $\left(\mathrm{CeO}_{1.9}\right.$, oxygen deficient $)$ surfaces in addition to stoichiometric $\left(\mathrm{CeO}_{2}\right)$ surfaces. Once these energies are evaluated, we explore how the equilibrium morphology changes as a function of $\mathrm{CO}_{2}$ chemical potential and thereby provide a prediction on what conditions are required to thermodynamically stabilize the high energy surfaces, for example the more reactive $\{100\}$.

\section{Methodology}

Bulk Models. The structure of stoichiometric bulk $\mathrm{CeO}_{2}$ retains the fluorite crystal structure (space group Fm-3m) despite a small expansion of the unit cell, which is well-documented effect for the $a b$ initio methodology employed in this study. ${ }^{61}$ The simulated lattice parameter $(\mathrm{a}=0.545 \mathrm{~nm})$ compares well with the experimental lattice parameter of $(\mathrm{a}=0.541 \mathrm{~nm}) .^{62}$

Surface Models. Model surface structures were generated using the METADISE code. ${ }^{63}$ 3D boundary conditions were used throughout, and the surfaces were modelled using the slab method $^{64}$ in which a finite number of crystal layers is used to generate two identical surfaces via the introduction of a vacuum gap perpendicular to the surface. A vacuum gap of $15 \AA$ was used to minimize the interaction between images. The $\{100\}$ and $\{110\}$ slabs with a $\mathrm{p}(2 \times 2)$ expansion of the surface unit cell included 13 and 7 atomic layers (24 and $28 \mathrm{CeO}_{2}$ units, respectively), while the $\{111\}$ slab with a $\mathrm{p}(2 \times 3)$ expansion included 12 atomic layers $\left(24 \mathrm{CeO}_{2}\right.$ units). The $\{100\}$ surface is a polar surface and has been modelled using previously established methodologies. ${ }^{61}$

The number of potential configurations for adsorbed carbon dioxide on surfaces of ceria is extremely large and many have been proposed in the literature. ${ }^{65} \mathrm{We}$ have studied the associative adsorption of $\mathrm{CO}_{2}$ on the surfaces of ceria i.e. $\mathrm{CO}_{2}$ molecules adsorbed onto a surface oxygen to form a carbonate $\left(\mathrm{CO}_{3}\right)$ species. We have also studied sub-stoichiometric surfaces of ceria, where an oxygen vacancy is introduced, which leaves two electrons that localize and reduce two cerium atoms from $\mathrm{Ce}^{4+}$ to $\mathrm{Ce}^{3+}$; these surfaces are referred to as reduced surfaces in this article and correspond to stoichiometry of $\mathrm{CeO}_{1.9}$. For reduced surfaces, configurations were constructed to ensure that a $\mathrm{CO}_{2}$ oxygen fills the vacancy. In some configurations where a carbonate was set at the start of the calculation, the surface oxygencarbon bond was found to break but the $\mathrm{CO}_{2}$ molecule remained loosely bound to the surface; these configurations are referred to as "molecular $\mathrm{CO}_{2}$ ".

Finally, to investigate the effect of $\mathrm{CO}_{2}$ chemical potential, four surface concentrations of $\mathrm{CO}_{2}$ were investigated for each surface: $0.13,0.25,0.38$ and $0.51 \mathrm{CO}_{2} / \mathrm{nm}^{2}$ on the $\{111\} ; 0.12$, $0.23,0.35$ and $0.47 \mathrm{CO}_{2} / \mathrm{nm}^{2}$ on the $\{110\}$; and $0.17,0.33,0.50$ and $0.67 \mathrm{CO}_{2} / \mathrm{nm}^{2}$ on the $\{100\}$. These concentrations correspond to $1,2,3$ and $4 \mathrm{CO}_{2}$ species on each surface. In each case, different adsorption geometries were investigated and corresponded to monodentate, bidentate and tridentate adsorption configurations.

Calculation details. Density functional theory (DFT) calculations were performed using the Vienna Ab-initio Simulation Package (VASP) code, ${ }^{66-67}$ within which projector augmentedwave pseudopotentials and a plane wave cutoff of $500 \mathrm{eV}$ were used with the sampling of the Brillouin zone sampled using a $5 \times 5 \times 5$ Monkhorst-Pack grid for the bulk materials $\left(\mathrm{CeO}_{2}\right.$ and $\mathrm{Ce}_{2} \mathrm{O}_{3}$ ) and $2 \times 2 \times 1$ for the slabs. Calculations were carried out using the generalized gradient approximation (GGA) exchangecorrelation functional of Perdew (PBE), with the $+\mathrm{U}$ correction of Dudarev ${ }^{68}$ to account for on-site Coulombic interactions. A $\mathrm{U}$ value of $5 \mathrm{eV}$ is applied to $\mathrm{Ce} \mathrm{f}$ states as this value has been utilized successfully in other studies. ${ }^{21,48,69-71}$

The structures were relaxed until the residual forces on each atom were less than $10 \mathrm{meV} \AA^{-1}$. All calculations were spin polarized and an initial ferromagnetic ordering was used throughout, which has been shown to produce no difference in the energetic of $\mathrm{CeO}_{2}$ systems. ${ }^{61}$

Surface Energies and Thermodynamic Framework. The surface energy $(\gamma)$ can be calculated from the energy of the systems containing the slab with $n$ Ce cations $\left(E_{\text {Slab }}\right)$ the energy per formula unit of ceria stoichiometric bulk $\left(E_{B u l k}\right)$ and the surface area $(A)$, according to eq 1 .

$\gamma_{\text {Bare }}=\frac{E_{\text {Slab }}-E_{\text {Bulk }}}{2 A}$

The calculated surface energy for the $\{111\},\{110\}$ and $\{100\}$ was $0.67,1.05$ and $1.41 \mathrm{Jm}^{-2}$ respectively. This is in agreement with previous computational work. ${ }^{21,69,72-73}$

Equation 1 provides the surface energy at $0 \mathrm{~K}$ and is not representative of the operating conditions of the various catalytic processes, and the synthesis and sintering conditions. In order to analyse the thermodynamic stability of the surfaces, when exposed to a given environment, it is important to account for the effects of the temperature and pressure of the surrounding atmosphere. This can be employed by applying ab initio atomistic thermodynamics. In this approach, the system is considered to be in thermodynamic equilibrium with a gas phase environment, which is treated as a reservoir, therefore exchanging particles with the system without changing its chemical potential. This strategy has been used in previous studies. ${ }^{21,71,74}$ The surface energy of a surface in equilibrium with an oxygen and carbon dioxide gas phase reservoir is calculated as follows:

$\gamma=\frac{E_{S l a b}-n E_{B u l k}-a O_{2} \mu O_{2}-b C O_{2} \mu C O_{2}}{2 A}$ 
where $\mathrm{aO}_{2}$ and $\mathrm{bCO}_{2}$ are the excess number of surface oxygen and carbon dioxide species in the slab, while $\mu \mathrm{O}_{2}$ and $\mu \mathrm{CO}_{2}$ are their respective chemical potentials. Equation 2 gives the surface energy at $0 \mathrm{~K}\left(\mathrm{~T}^{0}\right)$, temperature dependence is introduced as follows:

$\gamma=\frac{E_{\text {Slab }}-E_{\text {Bulk }}-a O_{2} \mu O_{2}-b \mathrm{CO}_{2} \mu \mathrm{CO}_{2}-a O_{2} \mu O_{2}(\mathrm{~T})-b \mathrm{CO}_{2} \mu \mathrm{CO}_{2}(\mathrm{~T})}{2 \mathrm{~A}}$

(3)

The chemical potential as a function of temperature is accounted for by the following formula (shown for $\mathrm{CO}_{2}$ where we have used previously for $\mathrm{CaCO}_{3}{ }^{75}$ but also used for $\mathrm{O}_{2}$ ):

$\mu_{\mathrm{CO}_{2}}^{0}(T)=\mu_{\mathrm{CO}_{2}}^{0}\left(T^{0}\right)+\Delta h_{\mathrm{CO}_{2}}\left(T^{0}, T\right)-T \cdot S_{\mathrm{CO}_{2}}(T)$

where $S_{\mathrm{CO}_{2}}$ and $\Delta h_{\mathrm{CO}_{2}}$ are taken from experimental tabulated data. ${ }^{76}$ If it is assumed that carbon dioxide and oxygen behave as ideal gases, then the effect of the gas partial pressure on its chemical potential is given by (again, only shown for $\mathrm{CO}_{2}$ ):

$\mu_{\mathrm{CO}_{2}}(T)=\mu_{C O_{2}}^{0}(T)+\frac{1}{2} k_{B} T \log \left(\frac{\rho_{\mathrm{CO}_{2}}}{\rho^{0}}\right)$

The difference in chemical potential due to temperature and partial pressure becomes:

$$
\Delta \mu_{\mathrm{CO}_{2}}(T)=\mu_{\mathrm{CO}_{2}}(T)-\mu_{\mathrm{CO}_{2}}^{0}\left(T^{0}\right)
$$

This is a complex dataset to visualise and it is often necessary to reduce the number of dimensions by fixing the partial pressure (or chemical potential) of one gas. We have looked at two extreme scenarios for carbon dioxide adsorption, adsorption on reduced surfaces (Low $\mathrm{O}_{2}$ pressure) and adsorption on stoichiometric surfaces (High $\mathrm{O}_{2}$ pressure).

The equilibrium crystal morphologies were generated based on the surface free energies calculated with equation 3 and constructed with a Wulff construction. ${ }^{64,77-78}$ The surface area of each surface as a function of temperature and pressure was calculated from the Wulff construction and these values were combined to give the surface area ratio between all surfaces under certain temperature and pressure.

Analysis was conducted using the surfinpy code. ${ }^{70}$ Wulff constructions were generated using the pymatgen $\operatorname{code}^{79}$ and all figures were drawn using VESTA. ${ }^{80}$

\section{Results and Discussion}

Surface Energetics on $\mathrm{CO}_{2}$ Sequestration. We considered mono, bi and tridentate adsorption of $\mathrm{CO}_{2}$ as a surface carbonate $\left(\mathrm{CO}_{3}\right)$ on stoichiometric and oxygen deficient $\mathrm{CeO}_{2}$ surfaces. At the lowest surface concentration of $\mathrm{CO}_{2}$ considered, we find that tridentate adsorption is always favoured on the three $\mathrm{CeO}_{2}$ surfaces (Figure 2). The geometry of the adsorbed $\mathrm{CO}_{3}$ is similar on the $\{110\}$ and $\{111\}$ surfaces, where the $\mathrm{CO}_{3}$ species is orientated at an angle to the surface (Figure $2 \mathrm{~b}$ and $\mathrm{c}$ ). In contrast, on the $\{100\}$ surface the carbonate ion adsorbs parallel to the surface (i.e. it lies flat) with each of the three $\mathrm{CO}_{3}$ oxygen atoms bridging between two surface cerium atoms. The calcu- lated $\mathrm{CO}_{3}$ geometry on each surface is in agreement with previous theoretical studies. ${ }^{44,48}$ Interestingly, a surface oxygen of the stoichiometric $\{100\}$ surface moves by $0.3 \AA$ to accommodate the carbonate (Figure $2 \mathrm{a}$ ). This rearrangement of the surface oxygen atoms has been previously reported on the addition of phosphate molecules ${ }^{69}$ but this is the first time that it has been shown that adsorbed $\mathrm{CO}_{2}$ modifies the surface structure of $\mathrm{CeO}_{2}$ to this extent.

Mullins et al. found that low exposures (5-20L) of $\mathrm{CO}_{2}$ at $180 \mathrm{~K}$ resulted in a tridentate carbonate species and a small amount of physisorbed $\mathrm{CO}_{2}$ at surface concentrations of $5 \mathrm{~nm}^{2}\left(\mathrm{CeO}_{2}\right)$ and $7.8 \mathrm{~nm}^{2}$ (CeO1.7). ${ }^{44}$ Our results indicate that $\mathrm{CO}_{2}$ adsorption geometry is concentration dependent. At low concentrations the entire $\mathrm{CO}_{2}$ population is predicted to adsorb in a tridentate geometry, but as the concentration increases, carbonate ions display a mixture of adsorption geometries, due to the competition between an increased number of $\mathrm{Ce}-\mathrm{O}$ bonds and a steric repulsion between $\mathrm{CO}_{3}$ ions. Thus, the surface concentration is a crucial consideration when attempting to rationalise the adsorption experiments probing the geometry.

In all calculations on $\{110\}$ and $\{100\}$ surfaces, we find that the carbonate species is the energetically preferred form of adsorbed $\mathrm{CO}_{2}$ and it is only on the $\{111\}$ surface at the highest concentration $\left(0.51 \mathrm{CO}_{2} / \mathrm{nm}^{2}\right)$ that we see a mixture of molecularly adsorbed $\mathrm{CO}_{2}$ and $\mathrm{CO}_{3}$ species, which is in agreement with experiment. $^{48}$

The reduced surfaces are oxygen deficient and the removal of oxygen leaves two undercoordinated cerium atoms. The most stable configurations of adsorbed $\mathrm{CO}_{2}$ are those that maximize the surface coordination of the undercoordinated cerium ions (Figure 2d-f). Any attempt to stabilise $\mathrm{CO}_{2}$ configurations with monodentate geometries relaxed into tridentate geometries or to less stable bidentate configurations. The average bond lengths between the carbonate oxygen and surface cerium atoms are smaller for monodentate adsorption configurations $(2.17 \AA)$ and longer for tridentate configurations $(2.5 \AA$ ). Thus showing, perhaps unsurprisingly, that it is more energetically favourable for the surface to regain its coordination with multiple long bonds, as opposed to smaller numbers of stronger bonds.

The adsorption energy of $\mathrm{CO}_{2}$ on stoichiometric and reduced $\mathrm{CeO}_{2}$ surfaces as a function of $\mathrm{CO}_{2}$ concentration is shown in Figure 3. The magnitude of the adsorption energy of $\mathrm{CO}_{2}$ follows the order $\{100\}>\{110\}>\{111\}$ at all concentrations and all surfaces. This can be explained by the change in coordination of surface cerium atoms upon $\mathrm{CO}_{2}$ adsorption. Cerium at the $\{111\}$ surface is 7 -fold coordinated, whereas is 6-fold coordinated on the $\{100\}$ and $\{110\}$ surfaces. More favourable $\mathrm{CO}_{2}$ adsorption energies at the $\{110\}$ and $\{100\}$ surfaces are due to surface cerium atoms increasing their coordination from 6 to $7 / 8$ depending on $\mathrm{CO}_{2}$ concentration. The $\mathrm{Ce}$ atoms at the $\{111\}$ surface are 7-fold coordinated with respect to oxygen, and thus there is a smaller energetic gain in recovering the 8-fold coordination. 
a

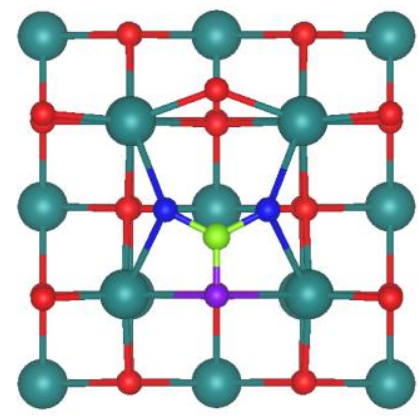

d

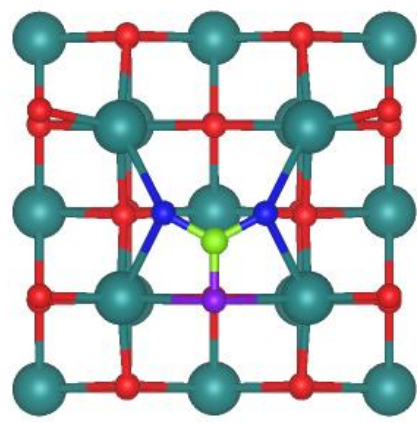

b

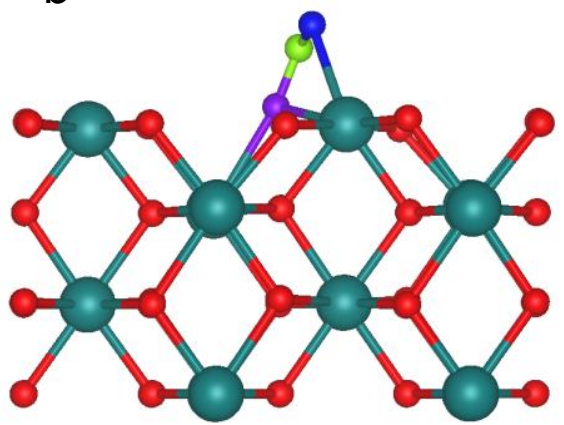

e

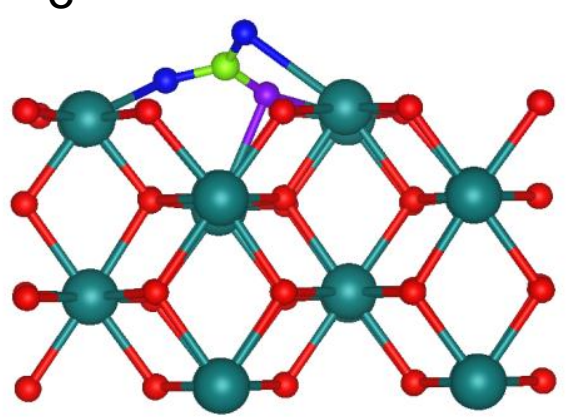

C

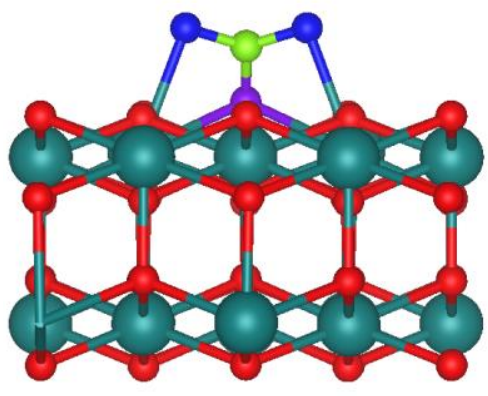

$f$

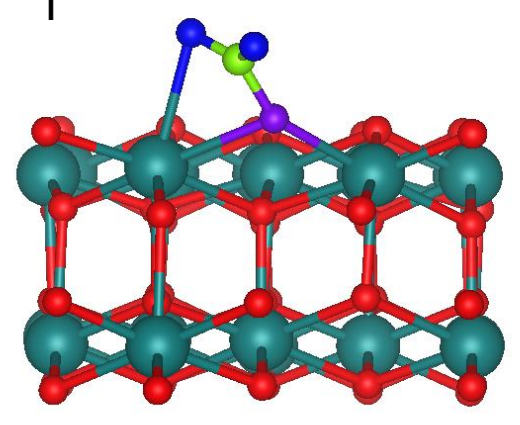

Figure 2 - Adsorption geometry for a single carbonate species on the stoichiometric $\left(\mathrm{CeO}_{2}\right)\{100\},\{110\}$ and $\{111\}$ (a, b, c) and reduced $\left(\mathrm{CeO}_{1.9}\right)\{100\},\{110\}$ and $\{111\}(\mathrm{d}, \mathrm{e}, \mathrm{f})$ surfaces. The $\{100\}$ surface is shown from above the surface plane and the $\{110\}$ and $\{111\}$ surfaces are shown from the side. For clarity, cerium, oxygen, and carbon atoms are displayed in dark green, red, and lime. Oxygen from the $\mathrm{CO}_{2}$ molecule are shown in blue and the surface oxygen bonded to the $\mathrm{CO}_{2}$ molecule is shown in purple. The view of the $\{100\}$ surface is in plane view (looking down), whereas the views of $\{110\}$ and $\{111\}$ are side on with the oxide surface perpendicular to the page.

At the lowest coverage considered, the adsorption energy on the $\{111\}$ and $\{100\}$ surfaces are in good agreement with previous work. ${ }^{44,48}$ However, Cheng et al. calculated the adsorption energy of $\mathrm{CO}_{2}$ on the $\{110\}$ surface and concluded that it is physisorbed as molecularly adsorbed $\mathrm{CO}_{2}$ and did not form a carbonate. ${ }^{49}$ In contrast, we find that the lowest adsorption energy corresponds to forming a carbonate ion. Indeed, we calculate that it is more stable by $1.06 \mathrm{eV}$ relative to the molecularly adsorbed $\mathrm{CO}_{2}$. Even including the van der Waals corrections, which are normally required for molecular adsorption, the difference when we applied the approach due to Klimes et al, only changed to $0.99 \mathrm{eV} .{ }^{81}$ Hence, we can be confident that carbonate formation is the thermodynamically preferred form this surface, in keeping with findings for the other low index surfaces.

The adsorption energy is more favourable on the reduced surfaces compared to the stoichiometric surfaces; this is again rationalised in terms of coordination. Reduction of $\mathrm{CeO}_{2}$ involves the removal of surface oxygen, which lowers the surface Ce coordination; $\mathrm{CO}_{2}$ adsorption heals this undercoordination by adsorbing an oxygen directly into the oxygen surface vacancy.

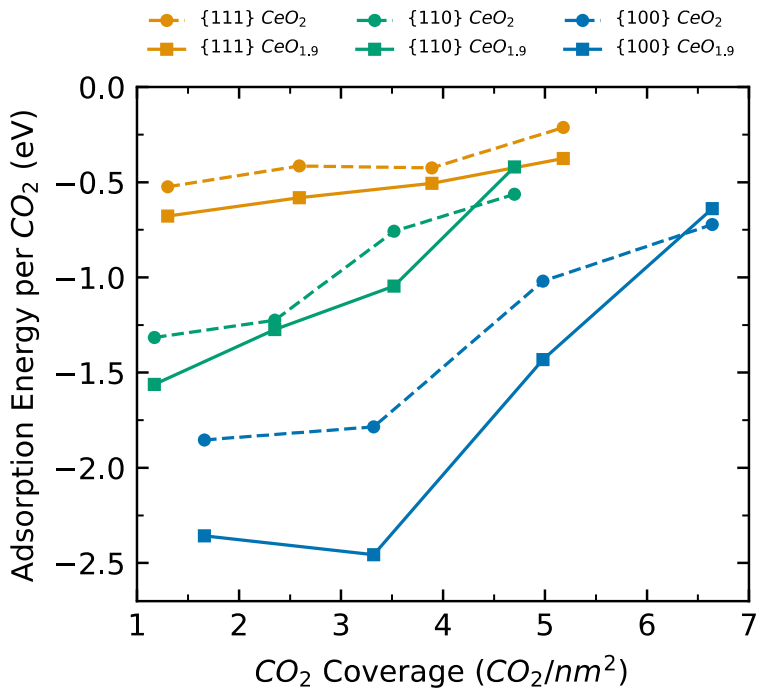

Figure 3 - Adsorption energies for $\mathrm{CO}_{2}$ adsorbing as a carbonate species on the stoichiometric (dashed lines) and reduced (solid lines) low index $\mathrm{CeO}_{2}$ surfaces. The $\{111\},\{110\}$ and $\{100\}$ surfaces are shown in orange, green and blue. 
Temperature and Pressure Dependent Stability of Adsorbed $\mathrm{CO}_{2}$. In order to investigate the surface stability as a function of temperature, oxygen and carbon dioxide partial pressures, we present phase diagrams for each surface. These phase diagrams account for a wide range of surface compositions, including stoichiometric and reduced, and also whether $\mathrm{CO}_{2}$ is present or not. Their surface free energies, as detailed in the methodology, can be expressed as a function of the chemical potential of adsorbed $\mathrm{CO}_{2}$ and surface $\mathrm{O}_{2}$.

Figure 4 shows the most stable surface compositions as a function of $\mathrm{CO}_{2}$ and $\mathrm{O}_{2}$ chemical potential differences $\left(\Delta \mu \mathrm{O}_{2}\right.$ and $\Delta \mu \mathrm{CO}_{2}$ ) for the three $\mathrm{CeO}_{2}$ surfaces. By relating chemical potential difference to partial pressure, $\Delta \mu=R T \ln \left(p_{x} / p^{0}\right)$, we see that low $\Delta \mu \mathrm{O}_{2}$ conditions (negative values on the phase diagram) corresponds to oxygen reducing conditions i.e. the surfaces are oxygen deficient. In contrast, at high $\Delta \mu \mathrm{O}_{2}$ (positive values on the phase diagram), which corresponds to oxidising conditions, the surface is fully oxidised, i.e. stoichiometric. At low $\Delta \mu \mathrm{CO}_{2}$ conditions, $\mathrm{CO}_{2}$ is not present at the surface. In both reducing and oxidising regimes, increasing $\Delta \mu \mathrm{CO}_{2}$ stabilizes the adsorption of $\mathrm{CO}_{2}$ on the surface. We can illustrate the change in composition of the surface phase by considering the temperature range: $298 \mathrm{~K}$ and $600 \mathrm{~K}$, which is typically of interest in catalytic processes and unit activities for the gases, i.e. partial pressures 1 bar. The resulting phase behaviour of the different surfaces between $298-600 \mathrm{~K}$ are marked with a black line on the phase diagrams in Figure 4. The $\{100\}$ surface, shows no change in surface stoichiometry (Figure 4c) over this temperature range, i.e. the most stable composition is 3.32 $\mathrm{CO}_{2} / \mathrm{nm}^{2}$ adsorbed at the reduced surface. The most stable surface composition of the $\{110\}$ surface is $2.35 \mathrm{CO}_{2} / \mathrm{nm}^{2}$ adsorbed at the stoichiometric surface at $298 \mathrm{~K}$, and on heating to $600 \mathrm{~K}$ is partially reduced and has $1.17 \mathrm{CO}_{2} / \mathrm{nm}^{2}$ adsorbed. For the $\{111\}$ surface the most stable composition has 1.30 $\mathrm{CO}_{2} / \mathrm{nm}^{2}$ adsorbed on the stoichiometric surface at $298 \mathrm{~K}$ and on heating to $600 \mathrm{~K}$ results in a bare stoichiometric surface with $\mathrm{CO}_{2}$ desorbed. Notably, on all three surfaces, at low T $(298 \mathrm{~K})$ when both gases are fixed to a pressure of 1 bar, adsorbed $\mathrm{CO}_{2}$ is stable on the surfaces. However, all surfaces behave in a very different way, indicating that this difference can be used to tune and control adsorption depending on what surfaces are expressed in the nanoparticles.

In general, the phase diagrams in Figure 4 illustrate that at sufficiently low $\Delta \mu \mathrm{O}_{2}$ values (reducing conditions $<-2.5 \mathrm{eV}$ ), i.e. low oxygen partial pressures, it is possible to transition between different $\mathrm{CO}_{2}$ coverages exclusively on the reduced surface by varying $\mu \mathrm{CO}_{2}$. Likewise, at sufficiently high $\Delta \mu \mathrm{O}_{2}$ values (oxidising conditions $>0.5 \mathrm{eV}$ ), it is possible to transition between different $\mathrm{CO}_{2}$ coverages by varying $\Delta \mu \mathrm{CO}_{2}$. Two component phase diagrams can also be visualized considering the chemical potential of one component as a function of temperature while maintaining constant the chemical potential of the other component. To isolate the effect of surface reduction on the adsorption of $\mathrm{CO}_{2}$, we fixed the chemical potential of oxygen and explored the adsorption of $\mathrm{CO}_{2}$ on the reduced surfaces (low $\Delta \mu \mathrm{O}_{2}$ ) and the stoichiometric surfaces (high $\Delta \mu \mathrm{O}_{2}$ ) as a function of temperature. This data can be tested using Temperature Programmed Desorption (TPD) experiments, and allows predictions to be made about the state of the surface under catalytically relevant temperatures. ${ }^{35}$ Figure 5a-f shows phase diagrams of $\mathrm{CO}_{2}$ partial pressure as a function of temperature for each surface, where the different regions of the diagrams represent the most stable surface composition (i.e. those with the lowest
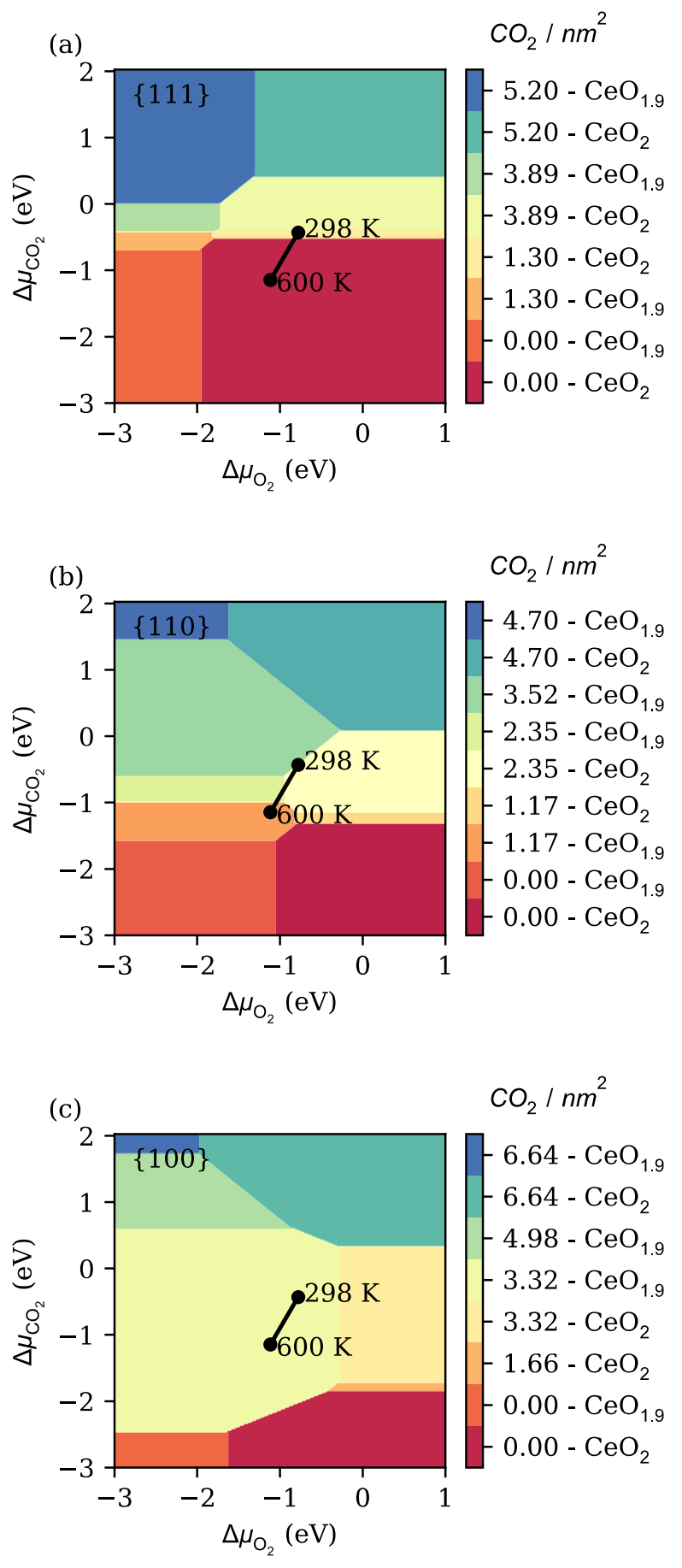

Figure 4 - Thermodynamic surface phase diagram of the $\mathrm{CeO}_{2}$ $\{111\}$ (a), $\{110\}$ (b) and $\{100\}$ (c) in a constrained equilibrium with $\mathrm{O}_{2}$ and $\mathrm{CO}_{2}$ gas phase. The differently shaded areas mark the stability regions of various surface structures for a given chemical potential of $\mathrm{O}_{2}$ and $\mathrm{CO}_{2}$. The black circles correspond to a $\mathrm{CO}_{2}$ and $\mathrm{O}_{2}$ pressure of 1 bar between 298 and $600 \mathrm{~K}$ and thus the transition between phases when the partial pressures of both gases are fixed, and the temperature is allowed to vary. 
(a)

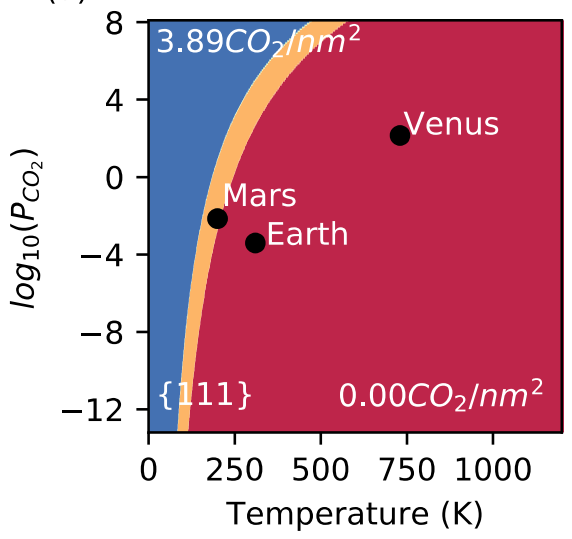

(d)

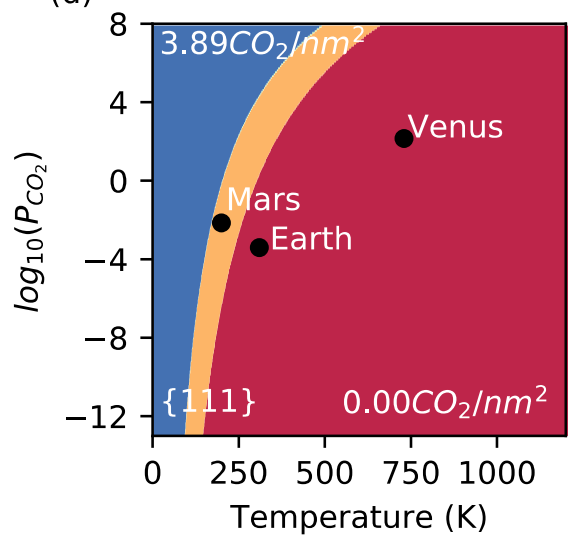

(b)

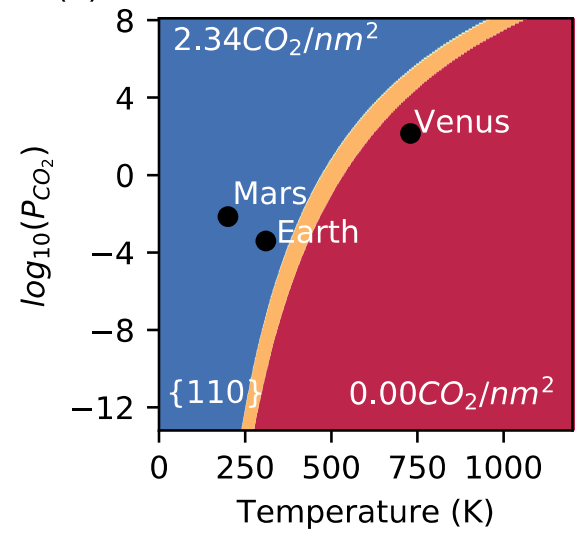

(e)

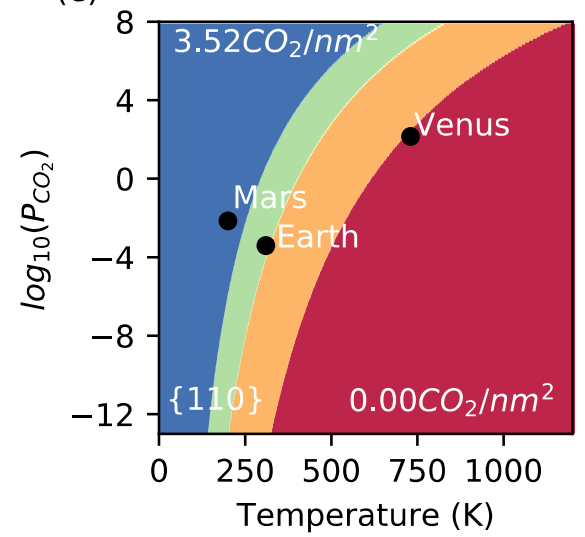

(c)

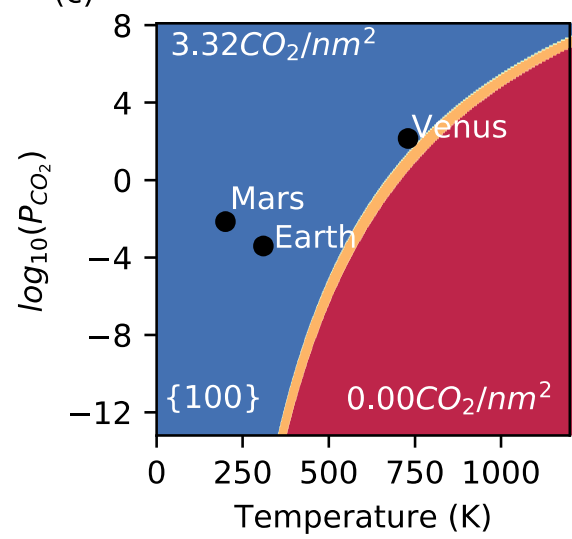

(f)

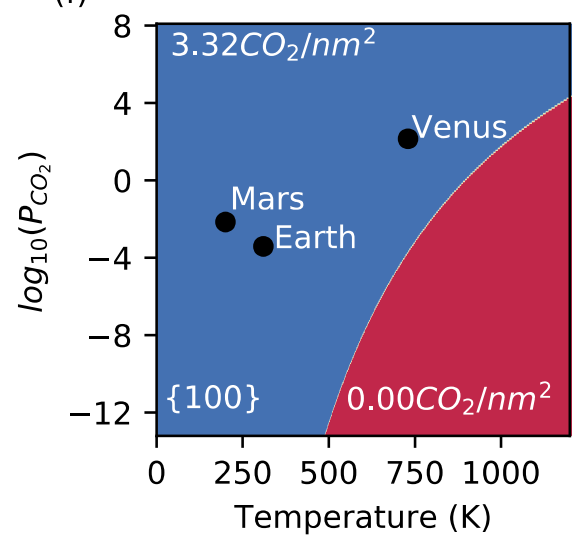

(g)

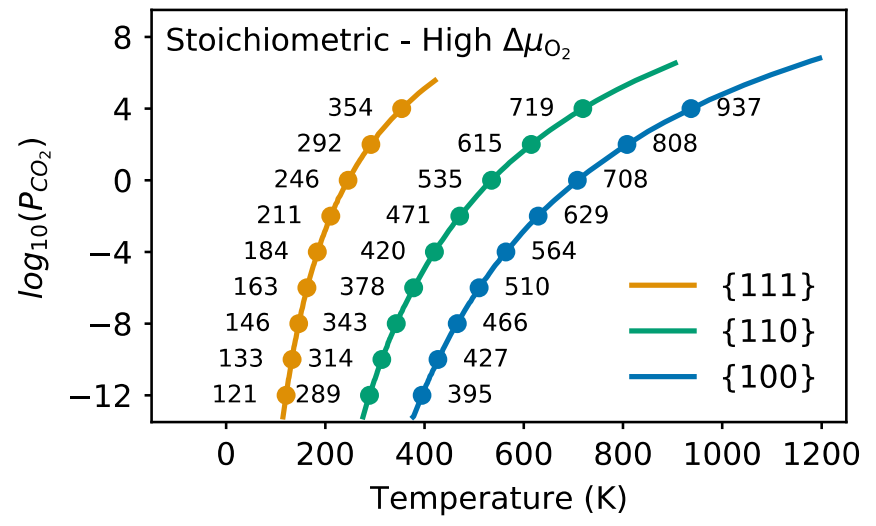

(h)

Figure 5 - Pressure vs Temperature phase diagrams for the stoichiometric $\left(\mathrm{CeO}_{2}\right)\{111\}$ (a), $\{110\}$ (b), $\{100\}$ (c)) and the reduced $\left(\mathrm{CeO}_{1.9}\right)\{111\}$ (d), $\{110\}$ (e) and $\{100\}$ (f) surfaces. The $\mathrm{CO}_{2}$ coverage $\left(\mathrm{CO}_{2} / \mathrm{nm}^{2}\right)$ of each phase is added to the phase diagram. Temperature of desorption for the stoichiometric $\left(\mathrm{CeO}_{2}\right)(\mathrm{g})$ and reduced $\left(\mathrm{CeO}_{1.9}\right)(\mathrm{h})$ surfaces. The ambient $\mathrm{CO}_{2}$ conditions at Venus, Earth and Mars surfaces have been added as reference points. The $\{111\},\{110\}$ and the $\{100\}$ surfaces are shown in green, orange and blue. The temperature of desorption at pressures ranging from -12 $\log _{10}\left(P_{\mathrm{CO}_{2}}\right)(\mathrm{bar})$ to $4 \log _{10}\left(P_{\mathrm{CO}_{2}}\right)(\mathrm{bar})$ in increments of 2 are marked at the corresponding locations on the plots.

surface energy at those specific values of temperature and pressure). At low $\mathrm{T}$ (blue region), the surfaces are partially covered with carbonate species, whereas at high $\mathrm{T}$ (red region) carbonate species are not stable at the surface and thus are not present. The transition between the two region represents the temperature range of desorption of $\mathrm{CO}_{2}$ from the surface. At high $\Delta \mu \mathrm{O}_{2}$ (stoichiometric surfaces), $\mathrm{CO}_{2}$ desorbs from the $\{111\}$ first, followed by the $\{110\}$ and then the $\{100\}$ at any given pressure (Figure $5 \mathrm{a}, \mathrm{b}, \mathrm{c}, \mathrm{g}$ ). At low $\Delta \mu \mathrm{O} 2$ (reduced surfaces), the introduction of oxygen vacancies greatly increases the temperature range that adsorbed carbonate is stable on the surfaces. This is due to the surface healing effect where $\mathrm{CO}_{3}$ species formed at the surface allow the surface cerium to regain their partial coordination (Figure $5 \mathrm{~d}, \mathrm{e}, \mathrm{f}$ ). Based upon the pressure vs temperature phase diagrams, we have calculated the temperature of desorption for $\mathrm{CO}_{2}$ (removal of carbonate from the surface) species at the $\{111\},\{110\}$ and $\{100\}$ surfaces as a function of $\mathrm{CO}_{2}$ pressure (Figure $5 \mathrm{~g} / \mathrm{h}$ ). The desorption temperatures 
represent the transition between a bare surface and a surface with $\mathrm{CO}_{2}$ adsorbed as a carbonate.

Senanayake and Mullins reported weakly bound $\mathrm{CO}_{2}$ on the $\{111\}$, which started desorbing at $150 \mathrm{~K}$ and was left with only a small amount of carbonate at $200 \mathrm{~K} .{ }^{43,65}$ Temperature Programmed Desorption experiments are typically run under UHV $\left(10^{-12}\right.$ bar $)$ and within our model we predict the removal of $\mathrm{CO}_{2}$ at $127 \mathrm{~K}$ on the $\{111\}$ at these conditions. Removal of $\mathrm{CO}_{2}$ at low temperatures on the $\{111\}$ is reported by Staudt et al. who could not detect any $\mathrm{CO}_{2}$ on the $\{111\}$ surface at $300 \mathrm{~K} .{ }^{82} \mathrm{Se}$ nanayake et al. determined that carbonates were removed from the $\{111\}$ surface of $\mathrm{CeO}_{\mathrm{x}} / \mathrm{Au}$ on heating to $300 \mathrm{~K} .{ }^{43}$ These observations are consistent with our findings as we predict that the partial pressures of $\mathrm{CO}_{2}$ would need to be above 100 bar to be confident of detecting carbonates at $300 \mathrm{~K}$.

We note that carbonate is bound much more strongly on the $\{100\}$ and thus the desorption temperatures are much higher at this surface compared to the $\{110\}$ and $\{111\}$. Albrecht et al. found that carbonate species on the $\{100\}$ are stable up to 600 $\mathrm{K}$ for stoichiometric ceria and $700 \mathrm{~K}$ for partially reduced ceria $\left(\mathrm{CeO}_{1.9}\right)$ under ultra-high vacuum conditions. ${ }^{44} \mathrm{We}$ predict under these conditions that $\mathrm{CO}_{2}$ desorbs by $450 \mathrm{~K}$ on stoichiometric ceria and $550 \mathrm{~K}$ on reduced ceria. It is worth noting that our reduced ceria model is $\mathrm{CeO}_{1.916}$ which is not as oxygen deficient as the experimental samples, and of course we have assumed that there are no impurities present either at the surface or in the gas. Clean $\{100\}$ surfaces are also difficult to synthesise, which arises from the flexibility of the surface oxygen network that can easily access many different surface oxygen arrangements with very small energy differences. ${ }^{20,35}$

Our calculations suggest that oxidation of the surface removes / hinders the adsorption of carbonates from / to the surface, as the reduced surfaces have considerably higher desorption temperatures compared to stoichiometric surfaces (up to $200 \mathrm{~K}$ ). Oxygen vacancies are reactive sites and are often desirable in catalytic reactions, however carbon dioxide interacts so strongly with the vacancies that the catalyst may lose its efficiency. It is clear that efficiency may be restored as the temperature increases (and $\mathrm{CO}_{2}$ desorbs). However, this comes at a higher cost as more energy is required to remove $\mathrm{CO}_{2}$ from reduced compared to stoichiometric surfaces. In the Water Gas Shift Reaction, Feng et al. have shown that ceria redox reactions proceed via a stable carbonate intermediate; the coverage of this intermediate is dependent on the surface $\mathrm{Ce}^{3+}$ concentration. ${ }^{45}$ We show that reduced surfaces have a considerably stronger interaction with carbonates compared to the stoichiometric surfaces and given that $\mathrm{Ce}^{3+}$ concentration is dependent on the concentration of oxygen vacancies, we can infer that the experimental observations of Feng et al., is likely to be attributed to the strong interaction between $\mathrm{CO}_{2}$ and the oxygen vacancies.

The effect of adsorbed carbon dioxide on the temperature to reduce the surfaces of ceria is shown in Figure 6. The plot gives the reduction temperature for the surfaces in the absence and presence of $\mathrm{CO}_{2}$. In all cases adsorbed $\mathrm{CO}_{2}$ lowers the reduction temperature effectively making the surface more susceptible to reduction. For example, at atmospheric partial pressures of oxygen, the introduction of $\mathrm{CO}_{2}$ lowers the reduction temperature by 53,98 and $191 \mathrm{~K}$ for the $\{111\},\{110\}$ and $\{100\}$ respectively. In general, sequestration of $\mathrm{CO}_{2}$ has greatest impact on the reduction temperatures of the $\{100\}$, whereas there is only a small change seen for the $\{111\}$ surface. This effect can be ascribed to surface coordination. $\mathrm{CO}_{2}$ molecules adsorbing as carbonates effectively introduce two oxygen atoms, which increase the coordination of surface Ce ions, and as noted earlier, the $\{100\}$ has the lowest Ce coordination and hence is most affected.

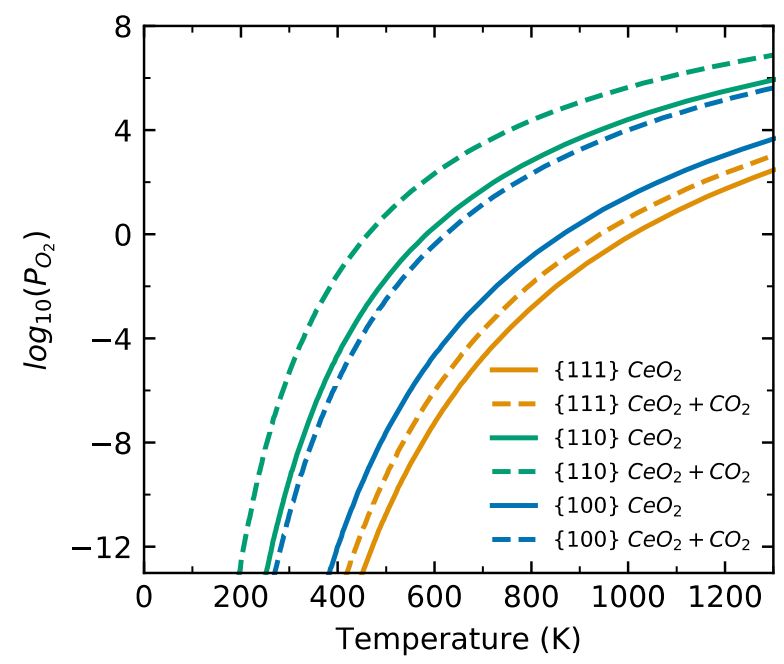

Figure 6 - The reduction temperatures at pressures ranging from $-12 \log _{10}\left(P_{O_{2}}\right)$ (bar) to $8 \log _{10}\left(P_{O_{2}}\right)$ (bar) in increments of 1 are marked at the corresponding locations on the plots. The reduction temperature is defined as the temperature required to reduce the stoichiometric surface through the removal of one surface oxygen atom.

A Thermodynamic Strategy to Predict Nanoparticle Morphology Evolution. The performance of $\mathrm{CeO}_{2}$ catalysts is influenced by particle morphology, as well as composition and stoichiometry of the exposed surfaces. ${ }^{17,20}$ Research has demonstrated that adjusting synthesis conditions gives rise to different $\mathrm{CeO}_{2}$ particle shapes, such as cubes ( $\left.\{100\}\right)$, octahedra $(\{111\})$ and rods (mixture of $\{110\}$ and $\{100\}),{ }^{83}$ and that different surfaces have different catalytic efficiencies. ${ }^{84-87} \mathrm{We}$ have combined a simple yet effective thermodynamic computational strategy for calculating surface free energies and applying them to the standard Wulff construction to suggest a synthetic pathway to generate nanoparticle morphologies as a function of experimentally tuneable conditions such as those of pressure and temperature. Clearly, the Wulff construction has a number of assumptions, not least it is based on equilibrium morphologies, but these are more likely to hold when considering nanoparticles and hence this process should help to guide the synthesis.

Based on the surface free energies calculated in the previous section, we have performed a Wulff construction as a function of temperature and partial pressure of $\mathrm{CO}_{2}$ at high fixed $\Delta \mu \mathrm{O}_{2}$ (oxidising conditions - stoichiometric surface.) and low fixed $\Delta \mu \mathrm{O}_{2}$ (reducing conditions - reduced surface). Figure 7 shows the effect of $\mathrm{CO}_{2}$ partial pressure on the equilibrium particle morphology; i.e. Figure 7 shows the thermodynamic driving force varies with conditions leading to different morphologies. The desorption temperature curves for each surface has been overlaid on each plot to illustrate the regions of the morphology phase diagram where each surface is being stabilized by carbonate species. For example, the stoichiometric $\{111\}$ surface has a very low $\mathrm{CO}_{2}$ desorption temperature whereas the $\{100\}$ 
surface has comparatively high desorption temperatures. The region of the phase

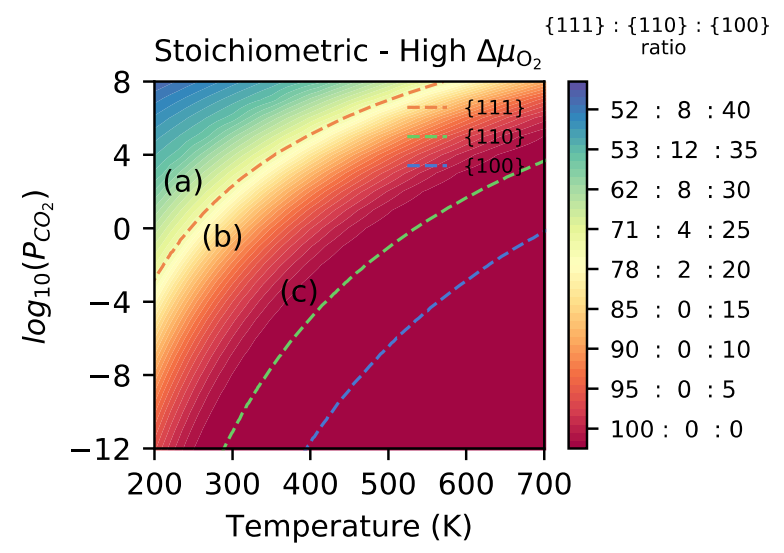

(a)
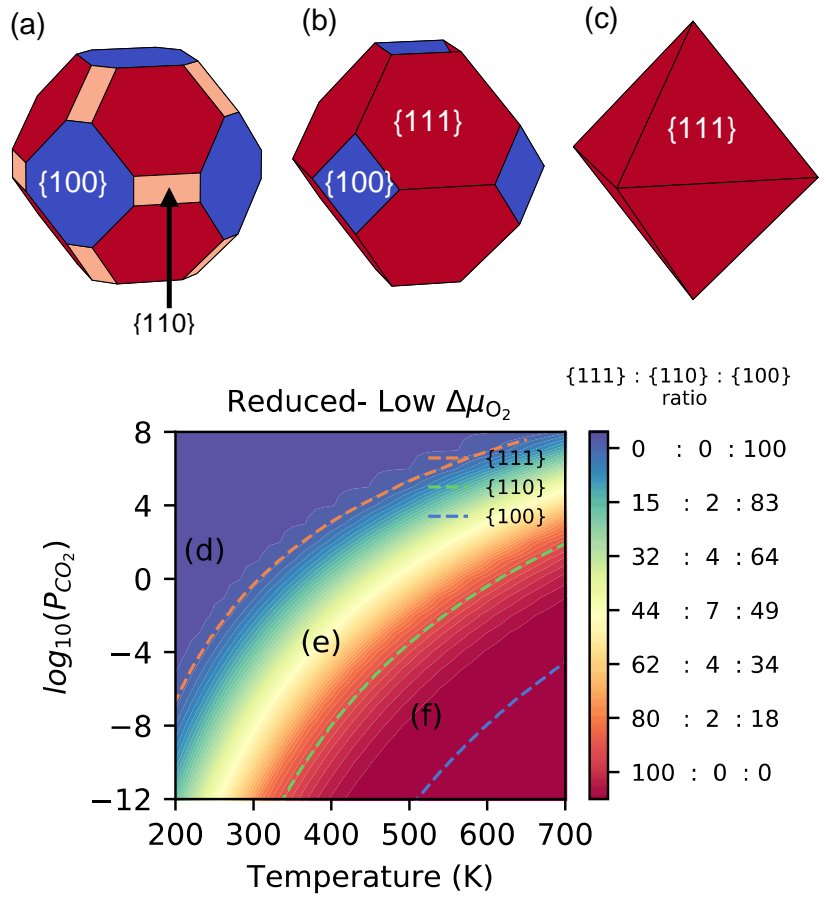

(d)

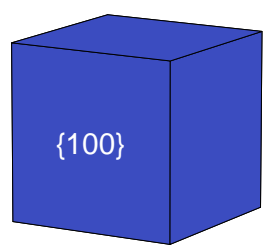

(e)

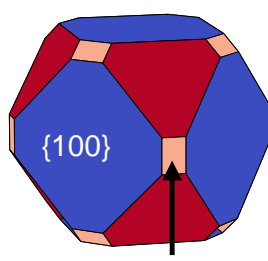

(f)

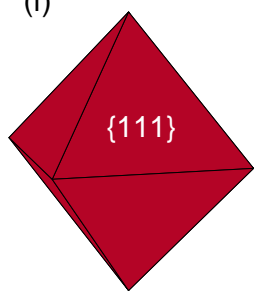

$\{110\}$ where carbonates are stable and thus influencing the morphology.

diagrams between these lines is the region where the surface energy of the $\{100\}$ is being lowered by adsorbed carbonate species while the $\{111\}$ is not. This lowering of one surface energy relative to another is why adsorbed species affect the equilibrium morphology significantly.

Using ultra high vacuum (UHV) conditions as a reference point (i.e. below $10^{-10} \log _{10}\left(P_{\mathrm{CO}_{2}}\right)$ (bar)), for stoichiometric $\mathrm{CeO}_{2}$, there is a clear preference for octahedral nanoparticles at temperatures above $210 \mathrm{~K}$. However, with increasing pressure, the surface of the nanoparticle is increasingly comprised of $\{100\}$ and $\{110\}$ surfaces. In the case of reduced $\mathrm{CeO}_{2}$, octahedral nanoparticles are stabilized above $400 \mathrm{~K}$ under UHV conditions. Thus to generate thermodynamically stable nano-octahedra displaying the most stable $\{111\}$ surface, it is necessary to limit the adsorption of $\mathrm{CO}_{2}$ molecules on the high energy $\{100\} /$ $\{110\}$ surfaces. Indeed, $\mathrm{CO}_{2}$ molecules on ceria cause an increase in the expression of the $\{100\}$ surface at the expense of the $\{111\}$ because of a disparity between the $\mathrm{CO}_{2}$ adsorption energy on each surface. Hence, high pressures of $\mathrm{CO}_{2}$, low temperatures and reduced ceria are a conceivable combination to generate highly reactive nanocubes.

Supercritical carbon dioxide. There is much interest from an environmental and sustainable point of view in using supercritical fluids (SCFs) in synthesis and processing. ${ }^{88}$ Part of the motivation for using SCFs, particularly in synthesis is that current methods for preparing metal salts often require very high temperatures and there can be additional challenges in separation and purification, especially for nanoparticles which are known to easily agglomerate. Supercritical $\mathrm{CO}_{2}\left(\mathrm{scCO}_{2}\right)$ has received less attention because generally metal salts are less soluble than in $\mathrm{scH}_{2} \mathrm{O}$ for example. However, we see (Figure 7) that nanocubes are the thermodynamically favoured particle shape at temperatures above $305 \mathrm{~K}$ and 75 bar $\left(\log _{10}\left(\mathrm{pCO}_{2}\right)\right.$ bar $\left.=1.8\right)$, which is where in its' phase diagram, $\mathrm{CO}_{2}$ becomes supercritical. Thus we predict that if ceria nanoparticles are processed in $\mathrm{scCO}_{2}$ then nanocubes will result. Clearly, there are a number of caveats, not least we have not as yet considered the effect of the presence of water or other hydrogen containing species, which may be a strong constraint on the purity of $\mathrm{scCO}_{2}$. We have also neglected other species such as $\mathrm{CO}$, although given that ceria is a well-known catalyst for converting $\mathrm{CO}$ to $\mathrm{CO}_{2}$, this should be less of an issue. Finally, we have assumed that with pure $\mathrm{scCO}_{2}$ the partial oxygen pressure is low and hence the reduced surface is favoured. However, even if we assume that reducing agents are not present, we note that $\mathrm{CO}_{2}$ confers a significant enhanced stability to the reduced $\{100\}$ surface, see Figure 5. Hence, if $\mathrm{O}_{2}$ partial pressures of less than 0.1 bar are present, it would result in the stabilization of the reduced $\{100\}$ at $450 \mathrm{~K}$ and at $\mathrm{CO}_{2}$ partial pressure of $10 \mathrm{kbar}$ perfect cubes are the thermodynamically favoured shape (figure 8). Thus, even if not used for synthesis but as a post synthetic treatment to clean the nanocubes, use of $\mathrm{scCO}_{2}$ should ensure that there is no degradation and will act to conserve the reactive $\{100\}$ surfaces.
Figure 7 - Particle morphology phase diagram for the stoichiometric and reduced surfaces. Wulff constructions are shown for the stoichiometric (high $\Delta_{\mu_{\mathrm{CO}_{2}}}$ ) and reduced (low $\Delta_{\mu_{\mathrm{CO}_{2}}}$ ) surfaces. These correspond to a $\{111\}:\{110\}:\{100\}$ ratio of 63:12:35 (a), 85:0:15 (b) and 100:0:0 (c) for the stoichiometric surface and 0:0:100 (d), 43:12:45 (e) and 100:0:0 (f) for the reduced surface. For clarify the $\{111\},\{110\}$ and $\{100\}$ facets are shown in red, orange and blue respectively. The desorption temperatures for the $\{111\}$ (orange), $\{110\}$ (green) and $\{100\}$ (blue) are shown on each phase diagram to illustrate the regions 


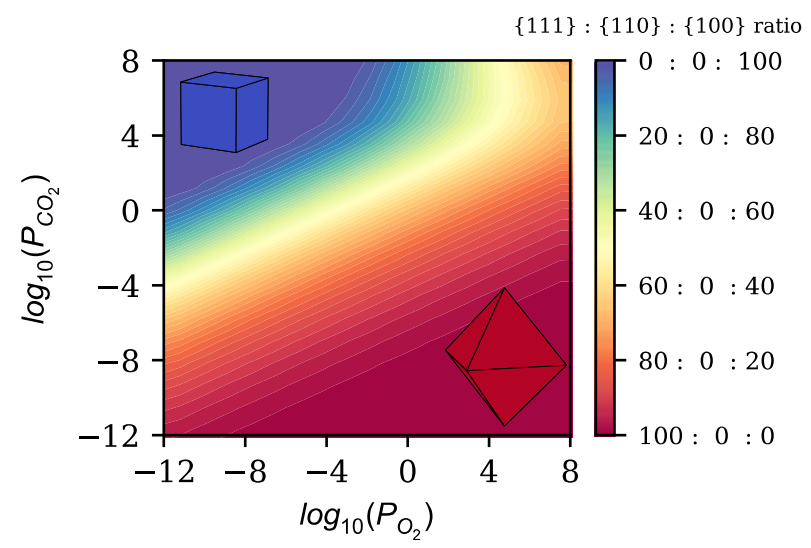

Figure 8 - Particle morphology phase diagram $\mathrm{CeO}_{2}$ as a function of oxygen and carbon dioxide partial pressure at $450 \mathrm{~K}$. Wulff constructions are shown for $\mathrm{CeO}_{2}$ nanocubes and octahedra

\section{Conclusions}

We have demonstrated using an important catalyst, $\mathrm{CeO}_{2}$, that atomistic modelling can capture the energetics of $\mathrm{CO}_{2}$ adsorption on ceria surfaces, and how that ultimately the change in surface stability drives a thermodynamic change in the shape of ceria nanoparticles. The results reveal that

1. Whether in oxidising or reducing conditions, $\mathrm{CO}_{2}$ is adsorbed as carbonate species on low index surfaces of ceria. There is an energetic cost to desorb $\mathrm{CO}_{2}$ from the surfaces following the order $\{100\}>\{110\}>$ $\{111\}$ and is correlated to cerium coordination number at the respective surfaces.

2. The presence of $\mathrm{CO}_{2}$ increases the reducibility of ceria surfaces; indeed, the scavenging of oxygen from carbonated surfaces of ceria occurs at lower temperatures.

3. Thermodynamic driven evolution of nanoparticles in catalytic processes will see $\{100\}$ surfaces promoted over $\{111\}$ at lower temperatures and higher $\mathrm{CO}_{2}$ partial pressures, while $\{111\}$ surfaces are promoted over $\{100\}$ surfaces at higher temperatures and lower $\mathrm{CO}_{2}$ pressures.

4. Processing ceria nanocubes in $\mathrm{scCO}_{2}$ is predicted to conserve the particle shape.

As the starting material (a nanoparticle) for a catalytic process must sustain a large number of catalytic cycles it is important to not only choose a shape that is reactive but also a shape that can be conserved during the process. Manipulation of catalyst nanoparticle of ceria will need to be optimized by bearing in mind these simple rules so that they can last longer in the catalytic process needed.

\section{AUTHOR INFORMATION}

\section{Corresponding Author}

* A.R.Symington@bath.ac.uk

* S.C.Parker@bath.ac.uk
Adam R. Symington: 0000-0001-6059-497X

Marco Molinari: 0000-0001-7144-6075

Stephen C. Parker: 0000-0003-3804-0975

\section{Author Contributions}

ARS carried out the simulations, designed and carried out the data analysis, ARS, MM and SCP devised the study and ARS wrote the manuscript with contributions from all authors.

\section{ACKNOWLEDGMENT}

We would like acknowledge AWE and EPSRC (EP/P007821/1, EP/R010366/1, EP/R023603/1) for funding. Computations were run on Balena HPC facility at the University of Bath and the ARCHER UK National Supercomputing Service (http://www.archer.ac.uk) via our membership of the UK's HEC Materials Chemistry Consortium (HEC MCC) funded by EPSRC (EP/L000202, EP/R029431). To the extent that this paper relies on the contribution of AWE then the copyright vests in the Crown Copyright 2020/AWE.

\section{REFERENCES}

1. Sayle, T. X. T.; Molinari, M.; Das, S.; Bhatta, U. M.; Möbus, G.; Parker, S. C.; Seal, S.; Sayle, D. C., Environment-Mediated Structure, Surface Redox Activity and Reactivity of Ceria Nanoparticles. Nanoscale 2013, 5, 6063-6073.

2. Morgan, L. M.; Molinari, M.; Corrias, A.; Sayle, D. C., Protecting Ceria Nanocatalysts - the Role of Sacrificial Barriers. ACS Applied Materials \& Interfaces 2018, 10, 32510-32515.

$3 . \quad$ Rodriguez, J. A.; Grinter, D. C.; Liu, Z.; Palomino, R. M.; Senanayake, S. D., Ceria-Based Model Catalysts: Fundamental Studies on the Importance of the Metal-Ceria Interface in Co Oxidation, the WaterGas Shift, Co2 Hydrogenation, and Methane and Alcohol Reforming. Chemical Society Reviews 2017, 46, 1824-1841.

4. Zhou, K.; Li, Y., Catalysis Based on Nanocrystals with WellDefined Facets. Angewandte Chemie International Edition 2012, 51, 602613.

5. $\quad$ Yuan, Q.; Duan, H.-H.; Li, L.-L.; Sun, L.-D.; Zhang, Y.-W.; Yan, C.-H., Controlled Synthesis and Assembly of Ceria-Based Nanomaterials. Journal of Colloid and Interface Science 2009, 335, 151167.

6. Litti, L.; Reguera, J.; García de Abajo, F. J.; Meneghetti, M.; Liz-Marzán, L. M., Manipulating Chemistry through Nanoparticle Morphology. Nanoscale Horizons 2020, 5, 102-108.

7. Li, Y.-F., First-Principles Simulations for Morphology and Structural Evolutions of Catalysts in Oxygen Evolution Reaction. ChemSusChem 2019, 12, 1846-1857.

8. $\quad$ Sayle, T. X. T.; Cantoni, M.; Bhatta, U. M.; Parker, S. C.; Hall, S. R.; Möbus, G.; Molinari, M.; Reid, D.; Seal, S.; Sayle, D. C., Strain and Architecture-Tuned Reactivity in Ceria Nanostructures; Enhanced Catalytic Oxidation of Co to Co2. Chemistry of Materials 2012, 24, 1811-1821.

9. Zhao, P.; Cao, Z.; Liu, X.; Ren, P.; Cao, D.-B.; Xiang, H.; Jiao, H.; Yang, Y.; Li, Y.-W.; Wen, X.-D., Morphology and Reactivity Evolution of Hcp and Fcc Ru Nanoparticles under Co Atmosphere. ACS Catalysis 2019, 9, 2768-2776.

10. Khan, I.; Saeed, K.; Khan, I., Nanoparticles: Properties, Applications and Toxicities. Arabian Journal of Chemistry 2019, 12, 908931.

11. Kannan, N.; Mukunthan, K. S.; Balaji, S., A Comparative Study of Morphology, Reactivity and Stability of Synthesized Silver Nanoparticles Using Bacillus Subtilis and Catharanthus Roseus (L.) G. Don. Colloids and Surfaces B: Biointerfaces 2011, 86, 378-383.

12. Stelmachowski, P.; Ciura, K.; Grzybek, G., MorphologyDependent Reactivity of Cobalt Oxide Nanoparticles in N2o Decomposition. Catalysis Science \& Technology 2016, 6, 5554-5560. 13. Mourdikoudis, S.; Pallares, R. M.; Thanh, N. T. K., Characterization Techniques for Nanoparticles: Comparison and

\section{ORCID}


Complementarity Upon Studying Nanoparticle Properties. Nanoscale 2018 10, 12871-12934.

14. Liu, S.; Wu, X.; Weng, D.; Ran, R., Ceria-Based Catalysts for Soot Oxidation: A Review. Journal of Rare Earths 2015, 33, 567-590.

15. LeValley, T. L.; Richard, A. R.; Fan, M., The Progress in Water Gas Shift and Steam Reforming Hydrogen Production Technologies - a Review. International Journal of Hydrogen Energy 2014, 39, 16983-17000. 16. Wu, Z.; Li, M.; Overbury, S. H., On the Structure Dependence of Co Oxidation over Ceo2 Nanocrystals with Well-Defined Surface Planes. Journal of Catalysis 2012, 285, 61-73.

17. Montini, T.; Melchionna, M.; Monai, M.; Fornasiero, P., Fundamentals and Catalytic Applications of Ceo2-Based Materials. Chemical Reviews 2016, 116, 5987-6041.

18. Karakoti, A. S.; Monteiro-Riviere, N. A.; Aggarwal, R.; Davis, J. P.; Narayan, R. J.; Self, W. T.; McGinnis, J.; Seal, S., Nanoceria as Antioxidant: Synthesis and Biomedical Applications. JOM 2008, 60, 33-37.

19. Trovarelli, A., Catalysis by Ceria and Related Materials.

20. Castanet, U., et al., Controlling the $\{111\} /\{110\}$ Surface Ratio of Cuboidal Ceria Nanoparticles. ACS Applied Materials \& Interfaces 2019, $11,11384-11390$

21. Symington, A. R.; Molinari, M.; Moxon, S.; Flitcroft, J. M.; Sayle, D. C.; Parker, S. C., Strongly Bound Surface Water Affects the Shape Evolution of Cerium Oxide Nanoparticles. The Journal of Physical Chemistry C 2020, 124, 3577-3588.

22. Asghar, M. S. A.; Inkson, B.; Seal, S.; Molinari, M.; Sayle, D.; Möbus, G., In-Situ Observation of Radiation Physics and Chemistry of Nanostructured Cerium Oxide in Water. Materials Research Express 2018 , 6,015032 .

23. Mai, H.-X.; Sun, L.-D.; Zhang, Y.-W.; Si, R.; Feng, W.; Zhang, H.-P.; Liu, H.-C.; Yan, C.-H., Shape-Selective Synthesis and Oxygen Storage Behavior of Ceria Nanopolyhedra, Nanorods, and Nanocubes. The Journal of Physical Chemistry B 2005, 109, 24380-24385.

24. Li, Y.; Shen, W., Morphology-Dependent Nanocatalysts: RodShaped Oxides. Chemical Society Reviews 2014, 43, 1543-1574.

25. Tauster, S. J.; Fung, S. C.; Garten, R. L., Strong Metal-Support Interactions. Group 8 Noble Metals Supported on Titanium Dioxide. Journal of the American Chemical Society 1978, 100, 170-175.

26. Majimel, J.; Lamirand-Majimel, M.; Moog, I.; Feral-Martin, C.; Tréguer-Delapierre, M., Size-Dependent Stability of Supported Gold Nanostructures onto Ceria: An Hrtem Study. The Journal of Physical Chemistry C 2009, 113, 9275-9283.

27. Akita, T.; Okumura, M.; Tanaka, K.; Kohyama, M.; Haruta, M., Analytical Tem Observation of Au Nano-Particles on Cerium Oxide. Catalysis Today 2006, 117, 62-68

$28 . \quad$ Akita, T.; Tanaka, K.; Kohyama, M.; Haruta, M., Analytical Tem Study on Structural Changes of Au Particles on Cerium Oxide Using a Heating Holder. Catalysis Today 2007, 122, 233-238.

29. Liotta, L. F.; Longo, A.; Macaluso, A.; Martorana, A.; Pantaleo, G.; Venezia, A. M.; Deganello, G., Influence of the Smsi Effect on the Catalytic Activity of a Pt(1\%)/Ce0.6zr0.4o2 Catalyst: Saxs, Xrd, Xps and Tpr Investigations. Applied Catalysis B: Environmental 2004, 48, 133-149. 30. Bhatta, U. M.; Reid, D.; Sakthivel, T.; Sayle, T. X. T.; Sayle, D.; Molinari, M.; Parker, S. C.; Ross, I. M.; Seal, S.; Möbus, G., Morphology and Surface Analysis of Pure and Doped Cuboidal Ceria Nanoparticles. The Journal of Physical Chemistry C 2013, 117, 24561-24569.

31. Bugnet, M.; Overbury, S. H.; Wu, Z. L.; Epicier, T., Direct Visualization and Control of Atomic Mobility at $\{100\}$ Surfaces of Ceria in the Environmental Transmission Electron Microscope. Nano Letters 2017, 17, 7652-7658.

32. Yang, C.; Yu, X.; Heißler, S.; Nefedov, A.; Colussi, S.; Llorca, J.; Trovarelli, A.; Wang, Y.; Wöll, C., Surface Faceting and Reconstruction of Ceria Nanoparticles. Angewandte Chemie International Edition 2017, $56,375-379$

33. Crozier, P. A.; Wang, R.; Sharma, R., In Situ Environmental Tem Studies of Dynamic Changes in Cerium-Based Oxides Nanoparticles During Redox Processes. Ultramicroscopy 2008, 108, 1432-1440.

34. Tinoco, M.; Fernandez-Garcia, S.; Lopez-Haro, M.; Hungria, A. B.; Chen, X.; Blanco, G.; Perez-Omil, J. A.; Collins, S. E.; Okuno, H.; Calvino, J. J., Critical Influence of Nanofaceting on the Preparation and Performance of Supported Gold Catalysts. ACS Catalysis 2015, 5, 35043513.

35. Mullins, D. R., The Surface Chemistry of Cerium Oxide. Surface Science Reports 2015, 70, 42-85.

36. Hernández-Giménez, A. M.; Lozano-Castelló, D.; BuenoLópez, A., Effect of $\mathrm{Co} 2, \mathrm{H} 2 \mathrm{o}$ and $\mathrm{So} 2$ in the Ceria-Catalyzed Combustion of Soot under Simulated Diesel Exhaust Conditions. Applied Catalysis B: Environmental 2014, 148-149, 406-414.

37. Capdevila-Cortada, M.; Vilé, G.; Teschner, D.; Pérez-Ramírez, J.; López, N., Reactivity Descriptors for Ceria in Catalysis. Applied Catalysis B: Environmental 2016, 197, 299-312.

38. $\quad$ Aramouni, N. A. K.; Touma, J. G.; Tarboush, B. A.; Zeaiter, J.; Ahmad, M. N., Catalyst Design for Dry Reforming of Methane: Analysis Review. Renewable and Sustainable Energy Reviews 2018, 82, 2570-2585. 39. Lavoie, J.-M., Review on Dry Reforming of Methane, a Potentially More Environmentally-Friendly Approach to the Increasing Natural Gas Exploitation. Frontiers in Chemistry 2014, 2

40. Liu, X.; Ruettinger, W.; Xu, X.; Farrauto, R., Deactivation of $\mathrm{Pt} / \mathrm{Ceo} 2$ Water-Gas Shift Catalysts Due to Shutdown/Startup Modes for Fuel Cell Applications. Applied Catalysis B: Environmental 2005, 56, 6975 .

41. Kim, C. H.; Thompson, L. T., Deactivation of Au/Ceox Water Gas Shift Catalysts. Journal of Catalysis 2005, 230, 66-74.

42. Ma, J.; Sun, N.; Zhang, X.; Zhao, N.; Xiao, F.; Wei, W.; Sun, Y., A Short Review of Catalysis for Co2 Conversion. Catalysis Today 2009, $148,221-231$

43. Senanayake, S. D.; Stacchiola, D.; Evans, J.; Estrella, M.; Barrio, L.; Pérez, M.; Hrbek, J.; Rodriguez, J. A., Probing the Reaction Intermediates for the Water-Gas Shift over Inverse Ceox/Au(111) Catalysts. Journal of Catalysis 2010, 271, 392-400.

44. Albrecht, P. M.; Jiang, D.-e.; Mullins, D. R., Co2 Adsorption as a Flat-Lying, Tridentate Carbonate on Ceo2(100). The Journal of Physical Chemistry C 2014, 118, 9042-9050.

45. Feng, Z. A.; Machala, M. L.; Chueh, W. C., Surface Electrochemistry of Co2 Reduction and Co Oxidation on Sm-Doped Ceo2-X: Coupling between Ce3+ and Carbonate Adsorbates. Physical Chemistry Chemical Physics 2015, 17, 12273-12281.

46. Cargnello, M., et al., Active and Stable Embedded Au@Ceo2 Catalysts for Preferential Oxidation of Co. Chemistry of Materials 2010, $22,4335-4345$.

47. Deng, W.; Flytzani-Stephanopoulos, M., On the Issue of the Deactivation of Au-Ceria and Pt-Ceria Water-Gas Shift Catalysts in Practical Fuel-Cell Applications. Angewandte Chemie International Edition 2006, 45, 2285-2289.

48. Hahn, K. R.; Iannuzzi, M.; Seitsonen, A. P.; Hutter, J., Coverage Effect of the $\mathrm{Co} 2$ Adsorption Mechanisms on Ceo2(111) by First Principles Analysis. The Journal of Physical Chemistry C 2013, 117, 1701-1711.

49. Cheng, Z.; Sherman, B. J.; Lo, C. S., Carbon Dioxide Activation and Dissociation on Ceria (110): A Density Functional Theory Study. The Journal of Chemical Physics 2013, 138, 014702.

50. $\quad$ Köck, E.-M.; Kogler, M.; Bielz, T.; Klötzer, B.; Penner, S., In Situ Ft-Ir Spectroscopic Study of Co2 and Co Adsorption on Y2o3, Zro2, and Yttria-Stabilized Zro2. The Journal of Physical Chemistry C 2013, 117 , 17666-17673.

51. Pacchioni, G., Physisorbed and Chemisorbed $\mathrm{Co} 2$ at Surface and Step Sites of the Mgo(100) Surface. Surface Science 1993, 281, 207-219.

52. $\quad$ Polfus, J. M.; Yildiz, B.; Tuller, H. L.; Bredesen, R., Adsorption of $\mathrm{Co} 2$ and Facile Carbonate Formation on Bazro3 Surfaces. The Journal of Physical Chemistry C 2018, 122, 307-314.

53. Yang, C.-C.; Yu, Y.-H.; van der Linden, B.; Wu, J. C. S.; Mul, G., Artificial Photosynthesis over Crystalline Tio2-Based Catalysts: Fact or Fiction? Journal of the American Chemical Society 2010, 132, 8398-8406. 54. $\quad$ Kotobuki, M.; Leppelt, R.; Hansgen, D. A.; Widmann, D.; Behm, R. J., Reactive Oxygen on a Au/Tio2 Supported Catalyst. Journal of Catalysis 2009, 264, 67-76.

55. Konova, P.; Naydenov, A.; Venkov, C.; Mehandjiev, D.; Andreeva, D.; Tabakova, T., Activity and Deactivation of Au/Tio2 Catalyst in Co Oxidation. Journal of Molecular Catalysis A: Chemical 2004, 213, 235-240.

56. Schumacher, B.; Denkwitz, Y.; Plzak, V.; Kinne, M.; Behm, R. J., Kinetics, Mechanism, and the Influence of $\mathrm{H} 2$ on the Co Oxidation Reaction on a Au/Tio2 Catalyst. Journal of Catalysis 2004, 224, 449-462. 57. Hakim, A.; Marliza, T. S.; Abu Tahari, N. M.; Wan Isahak, R. W. N.; Yusop, R. M.; Mohamed Hisham, W. M.; Yarmo, A. M., Studies on Co2 Adsorption and Desorption Properties from Various Types of Iron Oxides ( $\mathrm{Feo}, \mathrm{Fe} 2 \mathrm{o} 3$, and $\mathrm{Fe} 3 \mathrm{o} 4)$. Industrial \& Engineering Chemistry Research 2016, 55, 7888-7897.

58. Daniells, S. T.; Overweg, A. R.; Makkee, M.; Moulijn, J. A., The Mechanism of Low-Temperature Co Oxidation with $\mathrm{Au} / \mathrm{Fe} 2 \mathrm{o} 3$ Catalysts: A Combined Mössbauer, Ft-Ir, and Tap Reactor Study. Journal of Catalysis 2005, 230, 52-65. 
Schubert, M. M.; Venugopal, A.; Kahlich, M. J.; Plzak, V.; Behm, R. J., Influence of $\mathrm{H} 2 \mathrm{o}$ and $\mathrm{Co} 2$ on the Selective Co Oxidation in H2-Rich Gases over Au/A-Fe2o3. Journal of Catalysis 2004, 222, 32-40.

60. Wijnja, H.; Schulthess, C. P., Atr-Ftir and Drift Spectroscopy of Carbonate Species at the Aged $\Gamma$-Al2o3/Water Interface. Spectrochimica Acta Part A: Molecular and Biomolecular Spectroscopy 1999, 55, 861-872. 61. Nolan, M.; Grigoleit, S.; Sayle, D. C.; Parker, S. C.; Watson, G. W., Density Functional Theory Studies of the Structure and Electronic Structure of Pure and Defective Low Index Surfaces of Ceria. Surface Science 2005, 576, 217-229.

62. Nolan, M.; Parker, S. C.; Watson, G. W., Reduction of No2 on Ceria Surfaces. The Journal of Physical Chemistry B 2006, 110, 2256-2262. 63. Watson, G. W.; Parker, S. C.; Kresse, G., Ab Initio Calculation of the Origin of the Distortion of $\backslash$ Ensuremath $\{\backslash A l p h a\}$-Pbo. Physical Review B 1999, 59, 8481-8486.

64. Oliver, P. M.; Parker, S. C.; Mackrodt, W. C., Computer Simulation of the Crystal Morphology of Nio. Modelling and Simulation in Materials Science and Engineering 1993, 1, 755-760.

65. Senanayake, S. D.; Mullins, D. R., Redox Pathways for Hcooh Decomposition over Ceo2 Surfaces. The Journal of Physical Chemistry $C$ 2008, 112, 9744-9752.

66. Kresse, G.; Furthmüller, J., Efficient Iterative Schemes for Ab Initio Total-Energy Calculations Using a Plane-Wave Basis Set. Physical Review B 1996, 54, 11169-11186.

67. Kresse, G.; Hafner, J., Ab Initio Molecular-Dynamics Simulation of the Liquid-Metal--Amorphous-Semiconductor Transition in Germanium. Physical Review B 1994, 49, 14251-14269.

68. Dudarev, S. L.; Botton, G. A.; Savrasov, S. Y.; Humphreys, C. J.; Sutton, A. P., Electron-Energy-Loss Spectra and the Structural Stability of Nickel Oxide: An Lsda+U Study. Physical Review B 1998, 57, 15051509 .

69. Molinari, M.; Symington, A. R.; Sayle, D. C.; Sakthivel, T. S.; Seal, S.; Parker, S. C., Computer-Aided Design of Nanoceria Structures as Enzyme Mimetic Agents: The Role of Bodily Electrolytes on Maximizing Their Activity. ACS Applied Bio Materials 2019, 2, 1098-1106.

70. Parker, A. R. S. a. J. T. a. M. M. a. A. M. a. S. C., Surfinpy: A Surface Phase Diagram Generator. Journal of Open Source Software 2019, 4,1210 .

71. Tegner, B. E.; Molinari, M.; Kerridge, A.; Parker, S. C.; Kaltsoyannis, N., Water Adsorption on Ano2 $\{111\},\{110\}$, and $\{100\}$ Surfaces (an $=\mathrm{U}$ and $\mathrm{Pu})$ : A Density Functional Theory $+\mathrm{U}$ Study. The Journal of Physical Chemistry C 2017, 121, 1675-1682.

72. Molinari, M.; Parker, S. C.; Sayle, D. C.; Islam, M. S., Water Adsorption and Its Effect on the Stability of Low Index Stoichiometric and Reduced Surfaces of Ceria. The Journal of Physical Chemistry C 2012, 116, 7073-7082.

73. Nolan, M.; Parker, S. C.; Watson, G. W., The Electronic Structure of Oxygen Vacancy Defects at the Low Index Surfaces of Ceria. Surface Science 2005, 595, 223-232.

74. Moxon, S.; Symington, A. R.; Tse, J. S.; Dawson, J.; Flitcroft, J. M.; Parker, S. C.; Cooke, D. J.; Harker, R. M.; Molinari, M., The Energetics of Carbonated Puo2 Surfaces Affects Nanoparticle Morphology: A Dft+U Study. Physical Chemistry Chemical Physics 2020, 22, 77287737.
75. Kerisit, S.; Marmier, A.; Parker, S. C., Ab Initio Surface Phase Diagram of the $\{1014\}$ Calcite Surface. The Journal of Physical Chemistry $B$ 2005, 109, 18211-18213.

76. Linstrom, P. J.; Mallard, W. G., The Nist Chemistry Webbook: A Chemical Data Resource on the Internet. Journal of Chemical \& Engineering Data 2001, 46, 1059-1063.

77. $\quad$ Davies, M. J.; Kenway, P. R.; Lawrence, P. J.; Parker, S. C.; Mackrodt, W. C.; Tasker, P. W., Impurity Segregation to the Surfaces of Corundum-Structured Oxides. Journal of the Chemical Society, Faraday Transactions 2: Molecular and Chemical Physics 1989, 85, 555-563.

78. Titiloye, J. O.; Parker, S. C.; Osguthorpe, D. J.; Mann, S., Predicting the Influence of Growth Additives on the Morphology of Ionic Crystals. Journal of the Chemical Society, Chemical Communications 1991, 1494-1496.

79. Tran, R.; Xu, Z.; Radhakrishnan, B.; Winston, D.; Sun, W.; Persson, K. A.; Ong, S. P., Surface Energies of Elemental Crystals. Scientific Data 2016, 3, 160080.

80. Momma, K.; Izumi, F., Vesta 3 for Three-Dimensional Visualization of Crystal, Volumetric and Morphology Data. Journal of Applied Crystallography 2011, 44, 1272-1276.

81. Klimeš, J.; Bowler, D. R.; Michaelides, A., Van Der Waals Density Functionals Applied to Solids. Physical Review B 2011, 83, 195131.

82. Staudt, T.; Lykhach, Y.; Tsud, N.; Skála, T.; Prince, K. C.; Matolín, V.; Libuda, J., Ceria Reoxidation by Co2: A Model Study. Journal of Catalysis 2010, 275, 181-185.

83. Désaunay, T.; Bonura, G.; Chiodo, V.; Freni, S.; Couzinié, J. P.; Bourgon, J.; Ringuedé, A.; Labat, F.; Adamo, C.; Cassir, M., SurfaceDependent Oxidation of $\mathrm{H} 2$ on Ceo2 Surfaces. Journal of Catalysis 2013, 297, 193-201.

84. Sudarsanam, P.; Hillary, B.; Deepa, D. K.; Amin, M. H.; Mallesham, B.; Reddy, B. M.; Bhargava, S. K., Highly Efficient Cerium Dioxide Nanocube-Based Catalysts for Low Temperature Diesel Soot Oxidation: The Cooperative Effect of Cerium- and Cobalt-Oxides. Catalysis Science \& Technology 2015, 5, 3496-3500.

85. Monte, M.; Gamarra, D.; López Cámara, A.; Rasmussen, S. B.; Gyorffy, N.; Schay, Z.; Martínez-Arias, A.; Conesa, J. C., Preferential Oxidation of $\mathrm{Co}$ in Excess $\mathrm{H} 2$ over Cuo/Ceo2 Catalysts: Performance as a Function of the Copper Coverage and Exposed Face Present in the Ceo2 Support. Catalysis Today 2014, 229, 104-113.

86. Yi, G.; Yang, H.; Li, B.; Lin, H.; Tanaka, K.-i.; Yuan, Y., Preferential Co Oxidation in a H2-Rich Gas by Au/Ceo2 Catalysts: Nanoscale Ceo2 Shape Effect and Mechanism Aspect. Catalysis Today 2010, 157, 83-88.

87. Yi, G.; Xu, Z.; Guo, G.; Tanaka, K.-i.; Yuan, Y., Morphology Effects of Nanocrystalline Ceo2 on the Preferential Co Oxidation in $\mathrm{H} 2-$ Rich Gas over Au/Ceo2 Catalyst. Chemical Physics Letters 2009, 479, 128 132 .

88. Lane, M. K. M.; Zimmerman, J. B., Controlling Metal Oxide Nanoparticle Size and Shape with Supercritical Fluid Synthesis. Green Chemistry 2019, 21, 3769-3781. 
